\title{
Colonização de Raízes de Plantas Daninhas Cultivadas in vitro e em Vasos por Ralstonia solanacearum, Biovares 1, 2 e 3*
}

\author{
Edin F. Orozco Miranda ${ }^{1 * *}$, Armando Takatsu² \& Carlos H. Uesugi ${ }^{3}$ \\ ${ }^{1}$ Universidad de San Carlos de Guatemala, Facultad de Agronomia, Campus Universitario Zona 12, Guatemala, e-mail: \\ edin@ hotmail.com, ${ }^{2}$ Departamento de Agronomia Universidade Federal de Uberlândia, Campus Umuarama, CEP 38400-902, \\ Uberlândia MG, e-mail: atakatsu@ triang.com.br; ${ }^{3}$ Departamento de Fitopatologia, Instituto de Ciências Biológicas, \\ Universidade de Brasília, Campus Darcy Ribeiro, Brasília DF, CEP 70910-900, e-mail: uesugich@ unb.br
}

(Aceito para publicação em 06/01/2004)

Autor para correspondência: Edin Francisco Orozco Miranda

OROZCO M., E.F., TAKATSU, A. \& UESUGI, C.H. Colonização de raízes de plantas daninhas cultivadas in vitro e em vasos por Ralstonia solanacearum, biovares 1, 2 e 3. Fitopatologia Brasileira 29:121-127. 2004.

\section{RESUMO}

No presente trabalho, a colonização de raízes de espécies de plantas daninhas por estirpes das biovares 1, 2 e 3 de Ralstonia solanacearum foi avaliada in vitro e em casa de vegetação. $\mathrm{Na}$ condição in vitro, sementes foram submetidas à quebra de dormência, desinfestadas e semeadas em meio de cultura Murashige \& Skoog (MS) modificado. A bactéria foi inoculada, colocando uma porção da massa no meio MS ao lado das plântulas. A colonização de raízes foi avaliada visualmente de acordo com a concentração de bactérias ao redor e na extensão das raízes e comparada a uma escala diagramática que variou de 1 a 4 . Foi analisada a área abaixo da curva de colonização de raízes. Em casa de vegetação, populações de seis variantes das mesmas biovares foram quantificadas a partir de raízes de plantas daninhas. A bactéria foi inoculada nas raízes sem ferimentos, vertendo-se $100 \mathrm{ml}$ da suspensão bacteriana na concentração de aproximadamente $10^{8} \mathrm{ufc} / \mathrm{ml}$ por vaso. A avaliação foi feita aos 35 dias após a inoculação através do plaqueamento dos extratos diluídos das raízes e contagem posterior das colônias. Foram observados diferentes sintomas e níveis de colonização de raízes pela bactéria nas espécies de plantas estudadas. Os dois métodos permitiram o estudo da colonização de raízes com resultados análogos, sugerindo que ambos permitem obter resultados similares. Entretanto, a técnica in vitro é promissora como método auxiliar para a avaliação da colonização radicular de grande número de espécies botânicas por diferentes isolados de $R$. solanacearum.

Palavras-chave adicionais: hospedeiros alternativos, murcha bacteriana, cultivo in vitro, técnica.

\section{ABSTRACT}

Colonization of the roots of weed cultivated in vitro and in pots by Ralstonia solanacearum, biovars 1, 2 and 3

The colonization of weed roots by strains of biovars 1,2 and 3 of Ralstonia solanacearum was evaluated in vitro and in greenhouse conditions. In vitro, seed dormancy was broken, disinfested and sown in modified Murashige \& Skoog (MS) culture medium in test tubes. The bacteria were inoculated by transferring a portion of the mass on the MS medium adjacent to the seedlings. Root colonization was evaluated visually, according to the concentration of bacteria around and along the length of the roots and compared with a diagram scale with scores ranging from 1 to 4 . The area under the curve of root colonization (AUCRC) was calculated and analyzed. In the greenhouse, populations of six variants of the same biovars were quantified from the roots of the weeds. Plants were inoculated without wounding the roots, by pouring $100 \mathrm{ml}$ of bacterial suspension $\left(10^{8}\right.$ $\mathrm{cfu} / \mathrm{ml}$ ) per pot. Evaluation was done 35 days after inoculation, by plating diluted root extracts and counting the colonies. In the plants species studied, different symptoms and root colonization levels by the bacteria were observed. Although the two methods yielded similar results, the in vitro technique is promising as an auxiliary method of evaluation for root colonization of large numbers of botanic species by different strains of $R$. solanacearum.

\section{INTRODUÇÃO}

A murcha bacteriana (MB), causada por Ralstonia solanacearum (Smith) Yabuuchi et al. (1995), é considerada a principal doença de origem bacteriana no mundo desde a sua primeira descrição por Smith em 1896 (Kelman, 1953; Hayward, 1991). A importância do patógeno está relacionada ao grande

\footnotetext{
*Parte da Tese de Mestrado do primeiro autor. Universidade de Brasília (1997).

** Bolsista PEC/PG-MRE/DCT-MEC/CAPES
}

número de espécies botânicas afetadas (centenas de espécies de plantas pertencentes a mais de 50 famílias botânicas) causando perdas econômicas difíceis de quantificar (Kelman, 1953; Buddenhagen \& Kelman, 1964; Takatsu, 1984; Hayward, 1991; Hayward, 1994; Lopes, 1994; Lopes \& Takatsu, 1997). Segundo Kelman (1953), a morte prematura de plantas e redução de rendimento são as principais vias pelas quais a bactéria ocasiona as perdas. Ralstonia solanacearum se caracteriza como uma bactéria cosmopolita, extremamente variável, é vascular e associada ao sistema radicular de várias plantas cultivadas e 
daninhas principalmente nas regiões tropicais e subtropicais do mundo (Lopes \& Takatsu, 1997). Essas características, mais a falta de conhecimentos básicos sobre a ecologia e evolução do patógeno, dificultam o seu controle (Kelman,1953; Lopes, 1994). As culturas de importância econômica mais relatadas e afetadas pela $R$. solanacearum são: batata (Solanum tuberosum L.), tomate (Lycopersicon esculentum Mill.), berinjela (Solanum melongena L.), fumo (Nicotiana tabacum L.), pimentão (Capsicum annuum L.), pimenta (Capsicum frustescens L.), bananeira (Musa spp.), gengibre (Zingiber officinale Rosc.) e amendoim (Arachis hipogaea L.) (Kelman, 1953; Pereira, 1990; Hayward, 1991; Hayward, 1994; Lopes, 1994; Lopes \& Takatsu, 1997).

Em relação às plantas daninhas, existe pouca informação acerca das espécies botânicas hospedeiras existentes. As publicações referem-se à constatação da ocorrência de murcha em determinadas espécies, considerando estas como hospedeiras suscetíveis àquela estirpe encontrada no local ou agroecossistema (Quezado-Soares \& Lopes, 1994). Quanto aos níveis de suscetibilidade ao patógeno, as plantas daninhas podem ser: altamente suscetíveis e mostrar sintomas típicos de murcha bacteriana, como no caso de Crassocephalum crepidioides (Benth) S. Moore (Asteraceae); ser tolerantes e mostrar poucos sintomas de murchamento, como Portulaca oleracea L. (Portulacaceae) e existe crescente evidência de hospedeiras, as quais sob certas condições atuam como assintomáticas ou com leves sintomas de infecção, por exemplo, Solanum carolinense L. (Hayward, 1994; Tussime, 1997). Além disto, existe distribuição atípica da doença em certas hospedeiras, isto é, algumas espécies tendo apresentado indivíduos suscetíveis em um local, são assintomáticas em outro.

Estudos de colonização e sobrevivência de $R$. solanacearum permitem o conhecimento do comportamento das espécies cultivadas e plantas daninhas como hospedeiras ou não, de diferentes estirpes da bactéria encontradas na área ou região, e são essenciais para que se possa utilizar as culturas adequadas nos programas de rotação e eliminação de plantas daninhas. Para isso, é necessário se dispor de métodos seguros e rápidos de avaliação da colonização de raízes por diferentes biovares de $R$. solanacearum em grande número de espécies botânicas. A colonização de raízes de plantas tem sido pouco pesquisada. Existem várias definições acerca do termo colonização, todas dirigidas a situações específicas. Nesta pesquisa, colonização foi considerada como um processo de multiplicação e sobrevivência bacteriana, na forma epífita ou endófita na planta daninha, após inoculação com isolados de $R$. solanacearum com ou sem manifestação de sintomas de murcha ou outros relacionados à doença. O presente trabalho foi realizado visando caracterizar a colonização de estirpes das biovares 1,2 e 3 de $R$. solanacearum em raízes de várias espécies de plantas daninhas in vitro e em casa de vegetação.

\section{MATERIAL E MÉTODOS}

\section{Colonização de raízes de plantas daninhas por biovares de Ralstonia solanacearum in vitro}

As estirpes de $R$. solanacearum foram provenientes das coleções de bactérias fitopatogênicas da Universidade de Brasília (UnB), da Empresa Brasileira de Pesquisa Agropecuária (EMBRAPA/Hortaliças) e Centro de Pesquisa Agropecuária da Amazônia Oriental-PA (CPATU). Foram avaliados 18 estirpes de $R$. solanacearum pertencentes às biovares $1,2 \mathrm{e} 3$. As estirpes/ biovares, hospedeira e procedência estão apresentados na Tabela 1. Estirpes de cada biovar foram identificadas de acordo com a classificação de Hayward (1964) e preservadas em água destilada esterilizada, de acordo com o método de Wakimoto (1982). As culturas para uso de rotina foram mantidas em placas de Petri em incubadora a $30^{\circ} \mathrm{C}$.

No estudo de avaliação da colonização in vitro, os experimentos foram conduzidos no Laboratório de Fitopatologia da UnB. As espécies de plantas daninhas foram selecionadas com base na sua importância nos campos de cultura nas áreas dos Cerrados, na distribuição geográfica e algumas com antecedentes de serem boas hospedeiras de $R$. solanacearum, estas foram: mastruz (Lepidium virginicum L.), Brassicaceae; joá-de-capote [Nicandra physaloides (L.) Pers.], Solanaceae; maria-pretinha (Solanum americanum Mill.), Solanaceae; beldroega (Portulaca oleracea L.), Portulacaceae; camapú (Physalis angulata L.), Solanaceae; caruru (Amaranthus spp.), Amaranthaceae; amendoim-bravo (Euphorbia heterophylla L.), Euphorbiaceae; chocalho-de-cascavel (Crotalaria spectabilis Roth.), Fabaceae; picão-preto (Bidens pilosa L.), Asteraceae e capim-colchão (Digitaria horizontalis Willd), Poaceae.

Na obtenção de plantas daninhas foi realizada a quebra de dormência das sementes para algumas espécies: $C$. spectabilis por imersão em água destilada a $80^{\circ} \mathrm{C}$ por $5 \mathrm{~min} ; P$. oleracea por lavagem em água destilada por $12 \mathrm{~h}$ em agitador; $L$. virginicum por lavagem em água destilada em agitador até tirar a mucilagem das sementes; $N$. physaloides, $P$. angulata e $E$. heterophylla por lavagem em solução de água destilada e $\mathrm{KNO}_{3}$ $0,03 \%$ por $12 \mathrm{~h}$ em agitador até tirar a mucilagem das sementes; S. americanum e $D$. horizontalis por lavagem em solução de água destilada e $\mathrm{KNO}_{3} 0,03 \%$ por $12 \mathrm{~h}$ em agitador;Amaranthus spp. e B. pilosa lavagem em água destilada por $2 \mathrm{a} 4 \mathrm{~h}$ em agitador.

Os meios de cultura utilizados foram: 523 de Kado \& Heskett (1970), na produção de inóculo de $R$. solanacearum e o meio MS (Murashige \& Skoog, 1962) modificado, consistindo no uso de $50 \%$ dos macros e microelementos, sem fonte de carbono (Habe \& Uesugi, 2000), na produção de plântulas. Foi colocado $25 \mathrm{ml}$ do meio em tubos de vidro de $55 \mathrm{ml}$ de volume que foram esterilizados por autoclavagem a $121^{\circ} \mathrm{C}$ por $17 \mathrm{~min}$.

Após a quebra de dormência, as sementes foram desinfestadas com etanol $70 \%$ por $30 \mathrm{~s}$, imersas em hipoclorito de sódio $2 \%$ por 2 min e mais três lavagens sucessivas com água destilada autoclavada. Em seguida, foram colocadas no meio MS, sendo a germinação de sementes das plantas daninhas feitas em sala de incubação com lâmpadas fluorescentes fornecendo aproximadamente 40 ? moles. $\mathrm{m}^{-2} \cdot \mathrm{s}^{-1}$, a $24 ? 3^{\circ} \mathrm{C}$ e fotoperíodo de $16 \mathrm{~h}$.

As plântulas desenvolvidas de maneira homogênea no meio MS foram inoculadas com as diferentes estirpes de $R$. solanacearum. A inoculação foi feita entre oito e 22 dias após a germinação, de acordo com o desenvolvimento de cada espécie. 
Colonização de raízes de plantas daninhas cultivadas in vitro...

TABELA 1 - Estirpes de Ralstonia solanacearum estudadas na colonização in vitro de raízes de plantas daninhas

\begin{tabular}{|c|c|c|c|}
\hline ESTIRPE & BIOVAR & HOSPEDEIRA & PROCEDÊNCIA \\
\hline $\mathrm{CNPH}^{*} 31$ & 1 & Tomate (Lycopersicon esculentum) & Macapá, AP \\
\hline CNPH 76 & 1 & Tomate (L. esculentum) & Camocim S. Félix, PE \\
\hline CNPH 122 & 1 & Tomate (L. esculentum) & Pipiripau, DF \\
\hline CNPH 127 & 1 & Batata (Solanum tuberosum) & CNPH, DF \\
\hline UnB1103** & 1 & Tomate (L. esculentum) & São Luís, MA \\
\hline UnB 1033 & 1 & Tomate (L. esculentum) & Pipiripau, DF \\
\hline CNPH 66 & 2 & Batata (S. tuberosum) & Ibicoara, BA \\
\hline CNPH 87 & 2 & Berinjela (Solanum melongena) & Alexandre Gusmão, DF \\
\hline CNPH 92 & 2 & Batata (S. tuberosum) & PAD- DF \\
\hline CNPH 113 & 2 & Batata (S. tuberosum) & Mariental, PR \\
\hline CNPH 121 & 2 & Tomate (L. esculentum) & Vargem Bonita, DF \\
\hline UnB 964 & 2 & Batata (S. tuberosum) & Canoinhas, SC \\
\hline CNPH 35 & 3 & Tomate (L. esculentum) & Macapa, AP \\
\hline $\mathrm{CNPH} 47$ & 3 & Jiló (Solanum gilo) & Manaus, AM \\
\hline CNPH 51 & 3 & Berinjela (S. melongena) & Belém, PA \\
\hline CNPH 62 & 3 & Tomate (L. esculentum) & Petrolina, PE \\
\hline $\mathrm{UnB} 630$ & 3 & Tomate (L. esculentum) & $\mathrm{CPAAO}^{* * *}, \mathrm{PA}$ \\
\hline UnB 1102 & 3 & Tomate (L. esculentum) & São Luís, MA \\
\hline
\end{tabular}

Uma porção de massa bacteriana foi colocada no meio MS modificado, com auxílio de uma alça de níquel-cromo, ao lado das plântulas, próximo às raízes. Posteriormente, os tubos de ensaio inoculados e identificados foram colocados em uma câmara Percival Scientific modelo 1-37 LVL, com lâmpadas fluorescentes fornecendo aproximadamente 40 ? moles. $\mathrm{m}^{-2} \cdot \mathrm{s}^{-1} \mathrm{a}$ $25 ? 1{ }^{\circ} \mathrm{C}$ e fotoperíodo de $12 \mathrm{~h}$. Após a inoculação da bactéria, foram feitas oito leituras em intervalos de $48 \mathrm{~h}$.

A avaliação da colonização pela bactéria das raízes das plantas daninhas foi feita segundo a escala diagramática com notas de 1 a 4 , onde 1 foi equivalente a ausência de colonização de raízes, 2 ? 30\% de colonização, 3 ? 60\% e 4 ? 100\% de colonização do sistema radicular. Esta avaliação foi feita observando-se a turvação ao redor e ao longo das raízes com a luz incidida lateralmente sob um fundo escuro e comparada com a escala diagramática.

O delineamento experimental foi inteiramente casualizado em todos os experimentos, com quatro repetições, sendo cada repetição uma planta por tubo de ensaio.

A área abaixo da curva de colonização de raízes (AACCR), que foi considerada como equivalente à curva de progresso da doença, foi calculada com base nos dados de colonização de raízes de acordo com a escala diagramática para as quatro repetições e oito leituras, para cada estirpe de bactéria e espécie de plantas daninhas. A análise de variância foi realizada para os dois ensaios efetuados para cada espécie e a análise conjunta para todas as espécies para a variável AACCR, efetuando-se a comparação de médias de acordo com o teste de Tukey $(\mathrm{p} \leq 0,05)$. Para todos os casos, os dados foram analisados no Programa Statistical Analysis System (SAS), do SAS Institute (1989). Foram realizadas análises de correlação entre espécies botânicas, biovares, estirpes e unidade formadora de colônia (ufc).

\section{Colonização de raízes de plantas daninhas por Ralstonia solanacearum em vasos}

Foram utilizadas seis variantes de $R$. solanacearum, com resistência múltipla aos antibióticos, Estreptomicina (sulfato de estreptomicina), Rifaldin (rifampicina) e Sintomicetina (cloranfenicol), das biovares 1 (CNPH 127 e UnB 1103); 2 (CNPH 113 e UnB 964) e 3 (CNPH 51 e UnB 1102), que também foram utilizados na técnica in vitro. Esses isolados foram selecionados com base na sua dispersão geográfica, sua colonização in vitro e patogenicidade em plântulas de tomate tipo Santa Cruz, considerada medianamente resistente.

As espécies de plantas daninhas utilizadas foram as mesmas do método in vitro exceto $P$. angulata. Os ensaios foram conduzidos em casa de vegetação, com variações de temperatura entre $15 \mathrm{a} 38^{\circ} \mathrm{C}$. Sementes das plantas daninhas foram semeadas em vasos contendo cerca de $1,5 \mathrm{~kg}$ de solo peneirado, adubado 
e autoclavado. O delineamento experimental foi o inteiramente casualizado, com quatro repetições, seis variantes de $R$. solanacearum, mais o tratamento controle (sem inóculo). Cada parcela experimental consistiu em um vaso com cinco-oito plantas.

A inoculação das variantes de $R$. solanacearum foi feita 20 dias após a semeadura, vertendo-se $100 \mathrm{ml}$ de suspensão bacteriana na concentração de $10^{8} \mathrm{ufc} / \mathrm{ml}$ por vaso, sem ferimentos nas raízes. Aos 35 dias após inoculação, foi feita a coleta de raízes das plantas daninhas, retirando todo o sistema radicular. Para retirar o excesso de solo, as raízes foram lavadas e enxugadas com toalhas de papel. De cada amostra foi utilizada $10 \mathrm{~g}$ de radicelas. O material foi triturado e diluído para $10^{-1} \mathrm{e}$ $10^{-2} \mathrm{em}$ água destilada esterilizada. Destas diluições, alíquotas de $0,05 \mathrm{ml}$ foram plaqueadas, com três repetições cada, em meio 523 acrescido dos antibióticos: estreptomicina, rifampicina e cloranfenicol, 50,50 e $15 \mathrm{ppm}$, respectivamente, e dos fungicidas: benomil $(50 \mathrm{ppm})$ e chlorothalonil $(20 \mathrm{ppm})$. As placas foram incubadas em incubadora a $30^{\circ} \mathrm{C}$. As colônias de aspecto leitoso, brilhantes e fluidas foram contadas quatro dias após o plaqueamento. Para confirmação da bactéria $R$. solanacearum, realizaram-se testes de hipersensibilidade em folhas de fumo de acordo com Klement et al. (1964), cultivo em meio de tetrazolium (Kelman, 1954) e testes para determinação das biovares 1, 2 e 3 segundo Hayward (1964). As populações de R. solanacearum obtidas foram expressas em ufc/g de raiz.

A análise de variância foi feita para cada espécie avaliada e conjunta para as espécies de plantas daninhas e para a variável ufc/g de raiz. Utilizou-se o programa Statistical Analysis System (SAS) do SAS Institute (1989). Na análise estatística a população de $R$. solanacearum foi expressa em ufc/g de raiz e os dados foram transformados em $\log (\mathrm{X}+1)$. Na comparação de médias onde houve diferença significativa, foi realizado o teste de Tukey $(\mathrm{p} \leq 0,05 \%)$.

\section{RESULTADOS E DISCUSSÃO}

\section{Colonização de raízes por Ralstonia solanacearum e sintomas nas plantas daninhas in vitro}

$\mathrm{Na}$ avaliação in vitro, foram observados diferentes níveis de colonização da rizosfera das plantas daninhas pelas estirpes estudadas. Conforme a análise de variância conjunta dos valores da AACCR das dez espécies de plantas daninhas, o CV foi de 9,35 . Houve diferença significativa entre espécies, ensaios, biovares, isolados e nas interações: espécie-ensaio, espéciebiovar, espécie-estirpe $(\mathrm{p} \leq 0,05)$ (Figuras 1-2). Não houve diferença significativa nas interações ensaio-biovar e biovarestirpe na mesma probabilidade. De acordo com o teste de Tukey ( $\mathrm{p} \leq 0,05)$, para os valores de AACCR para colonização por espécie de planta daninha, houve a formação de vários grupos, isto mostra que ocorreram diferenças na colonização de acordo com a espécie botânica estudada. Os valores mais altos de AACCR corresponderam a $L$. virginicum, às espécies solanáceas e a $P$. oleracea. Estes resultados indicam que certas espécies são mais colonizadas pela bactéria e constitui-se em melhores hospedeiras. D. horizontalis, foi a espécie com a menor AACCR
(Figura 1A). As informações são concordantes com relatos de Hayward (1994) e Berg (1971), em relação à especificidade e patogenicidade da bactéria por determinadas espécies botânicas. Valores de AACCR para as biovares 1, 2, 3, foram estatisticamente diferentes. Para a maioria das espécies estudadas, as estirpes da biovar 3 apresentaram os maiores valores de AACCR (Figura 2A), indicando que tiveram melhor colonização de raízes em relação às outras. As estirpes, $\mathrm{CNPH} 127$ biovar 1; CNPH 51 e UnB 1102 biovar 3, apresentaram as médias mais altas de AACCR, enquanto que, o valor mais baixo foi para o CNPH 121 biovar 2 (Figura 2A), resultados análogos foram relatados por Melo et al. (1999). Na análise de correlação para estirpe e AACCR foi encontrado um coeficiente $\mathrm{R}=0,77$.

A

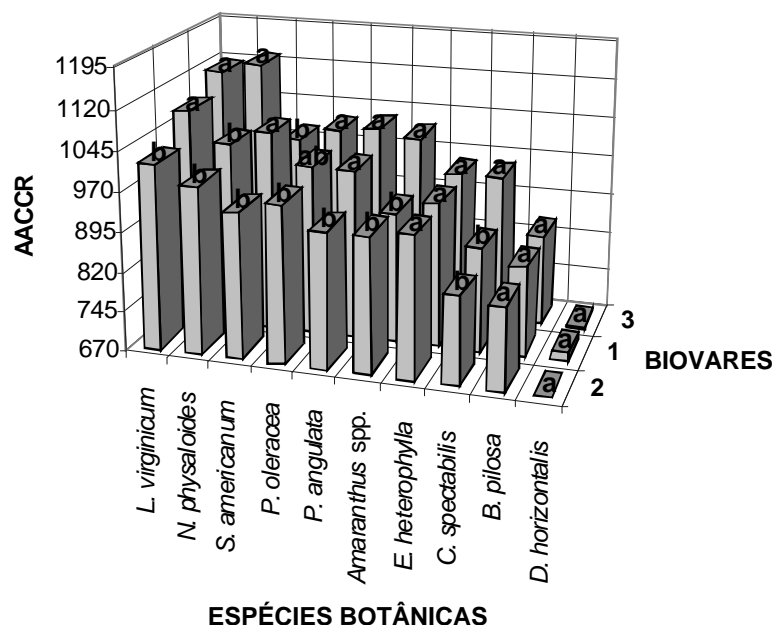

B

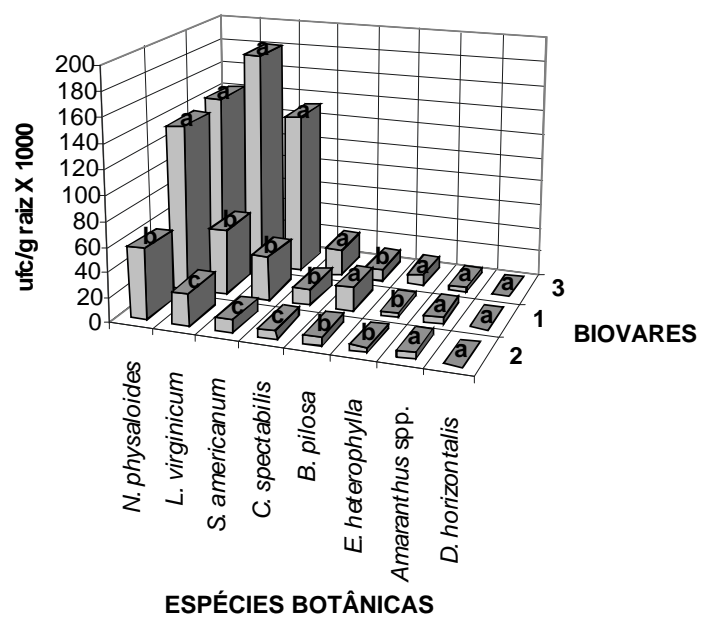

FIG. 1 - Análise conjunta da colonização de raízes de plantas daninhas por Ralstonia solanacearum das biovares 1, 2, e 3: (A) comparação de médias de área abaixo da curva de colonização de raízes (AACCR) por espécie botânica (Amaranthus spp., Bidens pilosa, Crotalaria spectabilis, Digitaria horizontalis, Euphorbia hererophylla, Lepidium virginicum, Nicandra physaloides, Portulaca oleracea, Physalis angulata, Solanum americanum) e biovares in vitro; (B) por estimativa da população bacteriana unidade formadora de colônia (ufc/g raiz x 100). Médias seguidas da mesma letra na vertical não diferem entre si, pelo teste de Tukey $(\mathrm{p} \leq 0,05)$. 
Colonização de raízes de plantas daninhas cultivadas in vitro...

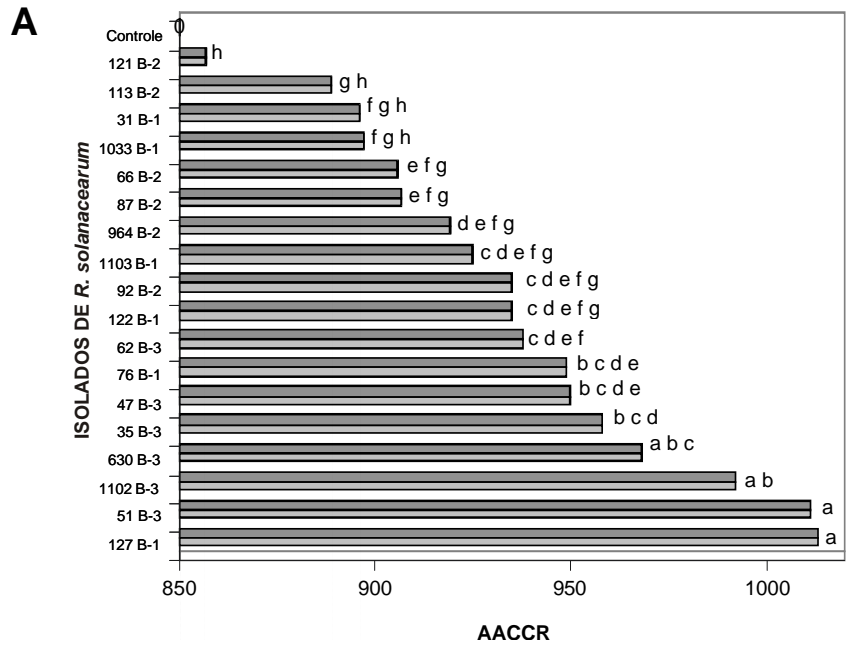

B

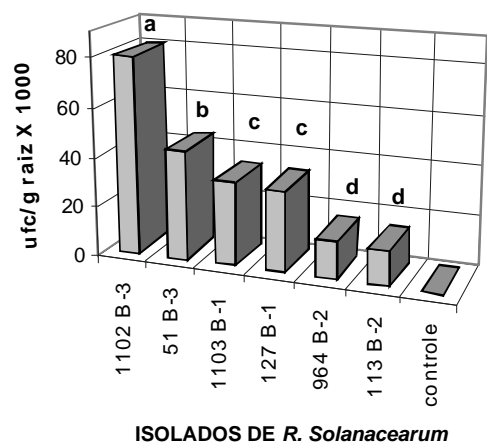

FIG. 2 - Análise da colonização de raízes de plantas daninhas por estirpes de Ralstonia solanacearum: (A) comparação de médias para a área abaixo da curva de colonização de raízes (AACCR), corresponde a 18 estirpes de $R$. solanacearum e dez espécies de plantas daninhas; (B) unidade formadora de colônia (ufc)/g raiz, seis variantes e oito plantas daninhas. Médias seguidas de mesma letra não diferem entre si pelo teste de Tukey $(\mathrm{p} \leq 0,05)$.

Algumas biovares colonizaram melhor algumas espécies de plantas daninhas. A biovar 3 teve os valores mais altos de AACCR para as espécies L. virginicum, N. physaloides, $P$. oleracea, P. angulata, Amaranthus spp., E. heterophylla, $C$. spectabilis e B. pilosa. A biovar $1 \mathrm{em} S$. americanum e $D$. horizontalis e foi analisada na interação espécie-biovar, onde foi encontrada diferença significativa $(\mathrm{p}<0,05)$ (Figura 1). Algumas estirpes independentemente da biovar foram bastante eficientes na colonização de algumas espécies de plantas. A estirpe UnB 1102 biovar 3 teve o valor mais alto de AACCR para $N$. physaloides, $P$. angulata e $P$. oleracea. A estirpe CNPH 127 biovar 1, em $S$. americanum e Amaranthus spp.; a estirpe CNPH 51 biovar 3 em $C$. spectabilis e $B$. pilosa e as estirpes CNPH 76 e UnB 1003 biovar 1, para D. horizontalis, situação que foi demonstrada na interação significativa de espécie-estirpe.

Sintomas observados em plantas daninhas na colonização in vitro foram: murcha em $P$. oleracea com quase todas as estirpes, enquanto que em $S$. americanum, $N$. physaloides e $L$. virginicum somente para algumas, nas demais espécies não foram observadas murchas. Houve clorose em L. virginicum, deformação de raízes em $C$. spectabilis, nanismo em $P$. angulata e proliferação de raízes adventícias em $S$. americanum, para algumas estirpes, sendo estas observações concordantes às citadas na literatura para culturas e plantas daninhas (Hayward, 1994; Quezado-Soares \& Lopes, 1994).

\section{Colonização de raízes por Ralstonia solanacearum e sintomas das plantas daninhas em vasos}

Os resultados obtidos e sintomas observados na avaliação da colonização de raízes por variantes de $R$. solanacearum em plantas daninhas em vasos foram análogos à colonização in vitro. Quanto aos sintomas, plantas de P. oleracea murcharam com todas as estirpes, dez a 20 dias após a inoculação da bactéria. Ocorreu ainda, necrose vascular do talo, podridão de raízes, necrose e queda de folhas, situação que não permitiu a quantificação de ufc em raízes e foi excluída para análise estatística. Entretanto, considera-se esta espécie uma boa hospedeira desta fitobactéria, principalmente no incremento de inóculo. As espécies restantes foram assintomáticas.

Na quantificação da colonização, a maior população de $R$. solanacearum ocorreu nas raízes de espécies de solanáceas e L. virginicum. A bactéria não foi reisolada de $D$. horizontalis. Conforme a análise conjunta dos valores de ufc/g de raiz para as espécies contempladas, o CV foi de 4,52 e houve diferença significativa entre espécies botânicas, biovares, estirpes e nas interações espécie-biovar, espécie-estirpe, biovar-estirpe $(\mathrm{p} \leq 0,05)$ (Figura1-2B). Houve diferenças nos tratamentos das populações de $R$. solanacearum entre as espécies de plantas daninhas. As maiores populações foram para as solanáceas e $L$. virginicum, o que indica que estas espécies são boas hospedeiras das estirpes de $R$. solanacearum avaliadas (Figura 1B). Entretanto não houve colonização pelo patógeno em $D$. horizontalis, indicando não ser uma boa hospedeira de $R$. solanacearum. Segundo Hayward (1994) e Quimio (1979), existe especificidade de $R$. solanacearum por determinadas espécies de plantas daninhas.

Na comparação de médias das biovares 1, 2 e 3, de acordo com o teste de Tukey $(\mathrm{p} \leq 0,05)$, as três foram diferentes. A biovar 3 apresentou a maior população e a menor foi para a biovar 2, resultado igual ao obtido através de análise de AACCR com o método in vitro (Figura1A e B). Assim, a biovar 2 (raça 3), por ser mais adaptada à cultura de batata, apresentou menores populações da bactéria nas diferentes espécies de plantas daninhas. As estirpes UnB 1102 e CNPH 51 da biovar 3 tiveram as maiores populações e as estirpes UnB 964 e CNPH 113 da biovar 2 as menores (Figura 2B). Nas interações espécie-biovar, espécie-estirpe, biovar-estirpe houve diferença significativa $(\mathrm{p} \leq 0,05)$, indicando que certas biovares apresentam maior população dependendo da espécie botânica.

De acordo com os resultados, os dois métodos permitiram a avaliação da colonização de raízes de plantas daninhas por $R$. solanacearum e os dados de ambos permitem gerar informações análogas. Pesquisar a colonização em vasos e contagem de ufc tem a desvantagem de não permitir a avaliação de grande número de estirpes e espécies botânicas, uma vez que é muito trabalhosa. Além disso, em algumas ocasiões, ocorrem problemas de 
bactérias contaminantes resistentes aos antibióticos que não permitem fazer as leituras na fase de reisolamento. Assim, o método de avaliação in vitro permite avaliar um grande número de biovares e estirpes, é menos trabalhoso, mais eficiente, econômico e os resultados são obtidos em menor tempo. Estas características também foram enfatizadas por Habe \& Uesugi (2000) e Bringel (2001). Portanto, é promissor como método auxiliar na avaliação da colonização radicular de grande número de espécies por diferentes estirpes de $R$. solanacearum. Porém, tem a desvantagem de oferecer dados qualitativos e erros subjetivos que podem ser cometidos na tomada de leituras e no uso de escalas diagramáticas. Isto pode ser evitado melhorando a técnica e procurando alguma forma de avaliação quantitativa da colonização. Em alguns casos a desinfestação das sementes é difícil. Contaminação por microrganismos pode gerar metabólitos que são tóxicos e causar a morte das plântulas e ou do patógeno alvo.

Pode-se afirmar que as raízes da maioria das espécies de plantas daninhas permitiram a colonização de $R$. solanacearum favorecendo a sobrevivência da bactéria com ou sem manifestação de sintomas, tal como relatado por outros pesquisadores (Buddenhagen, 1960; Berg, 1971; Granada \& Sequeira, 1983; Hayward, 1994). A espécie D. horizontalis, não foi hospedeira das biovares e estirpes de $R$. solanacearum avaliadas. Entretanto, as outras espécies que foram avaliadas são hospedeiras, sendo que algumas mais colonizadas pelo patógeno. Em áreas infestadas com $R$. solanacearum no campo e em associação com estas espécies pesquisadas, situações similares podem ocorrer. Com isto, incremento do inóculo inicial para culturas hospedeiras pode acontecer. Assim, em termos práticos e de acordo com os resultados, o controle eficiente das plantas aqui relatadas como hospedeiras em programas de rotação de culturas para o controle de $R$. solanacearum é de muita importância. Estudos de sobrevivência da bactéria com estas e outras plantas daninhas devem ser feitos em condições de campo. Os resultados obtidos nesta pesquisa reforçam as informações na literatura de que a sobrevivência da bactéria nas áreas infestadas se dá nas raízes de plantas daninhas em forma epifítica ou endofítica.

\section{REFERÊNCIAS BIBLIOGRÁFICAS}

BERG, L.A. Weed hosts of the strain of Pseudomonas solanacearum, causal organism of bacterial wilt of bananas. Phytopathology 61:1314-1315. 1971.

BRINGEL, J.M., TAKATSU, A. \& UESUGI, C.H. Colonização radicular de plantas cultivadas por Ralstonia solanacearum, biovares 1, 2 e 3. Scientia Agricola 58:497-500. 2001.

BUDDENHAGEN, I.W. \& KELMAN, A. Biological and physiological aspects of bacterial wilt caused by Pseudomonas solanacearum. Annual Review of Phytopathology 2:203-231. 1964.

BUDDENHAGEN, I.W. Strains of Pseudomonas solanacearum in indigenous hosts in banana plantations of Costa Rica, and their relationship to bacterial wilt of bananas. Phytopathology 50:660664. 1960.
GRANADA, G.A. \& SEQUEIRA, L. Survival of Pseudomonas solanacearum in soil, rhizosphere, and plant roots. Canadian Journal of Microbiology 29:433-440. 1983.

HABE, M. \& UESUGI, C.H. Método in vitro para avaliar a capacidade colonizadora de bactérias em raízes de tomateiro. Fitopatologia Brasileira 25:657-660. 2000.

HAYWARD, A.C. Biology and epidemiology of bacterial wilt caused by Pseudomonas solanacearum. Annual Review of Phytopathology 29:65-87. 1991.

HAYWARD, A.C. Characteristics of Pseudomonas solanacearum. Journal of Applied Bacteriology 27:265-277. 1964.

HAYWARD, A.C. The hosts of Pseudomonas solanacearum. In: Hayward, A.C. \& Hartman, G.L. (Eds.). Bacterial wilt: The disease and its causative agent, Pseudomonas solanacearum. CAB International/ AVRDC. 1994. pp. 9-24.

KADO, C.L. \& HESKETT, M.G. Selective media for isolation of Agrobacterium, Corynebacterium, Erwinia, Pseudomonas and Xanthomonas. Phytopathology 60:969-976. 1970.

KELMAN, A. The bacterial wilt caused by Pseudomonas solanacearum: a literature review and bibliography. North Caroline Agricultural Experimental Station.. Technical Bulletin 99. 1953.

KELMAN, A. The relationship of pathogenicity of Pseudomonas solanacearum to colony appearance on a tetrazolium medium. Phytopathology 44:693-695. 1954.

KLEMENT, Z., FARKAS, G.L. \& LOVREKOVICH Hypersensitive reaction induced by phytopathogenic bacteria in the tobacco leaf. Phytopathology 54:474-477. 1964.

LOPES, C.A. \& TAKATSU, A. Controle da murcha bacteriana. Fitopatologia Brasileira 22:224-225. 1997 (Resumo).

LOPES, C.A. Situação da murcha bacteriana no Brasil. In: Enfermedades bacterianas de la papa. Memórias del taller sobre enfermedades bacterianas de la papa. CNPH/EMBRAPA-CIP, Brasília, Brasil. 1994.

MELO, M.S. de, TAKATSU, A., UESUGI, C.H., FURUYA, N. \& MATSUYAMA, N. Population dynamics of Ralstonia solanacearum isolates in root systems of various crops. Bulletin of the Institute of Tropical Agriculture Kyushu University 22:4550. 1999.

MURASHIGE, T \& SKOOG, F. A revised medium for rapid growth and bioassays with tobacco tissue cultures. Physiologia Plantarum 15:473-497. 1962.

PEREIRA, L.V. Efeito do controle de plantas daninhas na disseminação do moko da bananeira. Fitopatologia Brasileira 15:203-206. 1990.

QUEZADO-SOARES, A.M. \& LOPES, C.A. Murcha bacteriana (Pseudomonas solanacearum) em duas espécies de plantas daninhas da família Labiatae. Fitopatologia Brasileira 19:581-584. 1994.

QUIMIO, A.J. \& CHAN, H.H. Survival of Pseudomonas solanacearum E.F. Smith in the rhizosphere of some weeds and economic plant species. Philippine Phytopathology 15:108-121. 1979.

TAKATSU, A., SILVA, C.B. \& REIFSCHNEIDER, F.J.B. Variabilidade e distribuição de Pseudomonas solanacearum de solanáceas cultivadas nas diferentes regiões do Brasil. Fitopatologia Brasileira 9:387. 1984. (Resumo)

TUSSIME, G., ADIPALA, E., OPIO, F. \& BHAGSARI, A. S. 
Colonização de raízes de plantas daninhas cultivadas in vitro...

Weeds as latent hosts of Ralstonia solanacearum in highland Uganda: Implications for lowland potato bacterial wilt control. In: Second International Bacterial Wilt Symposium. GuadaloupeAntilles Françaises. 22-27 de june. 1997.

WAKIMOTO, S., UTATSU, K., MATSUO, N. \& HAYASHI, N. Multiplication of Pseudomonas solanacearum in pure water. Annals of The Phytopathological Society of Japan 48:620-627. 1982.
YABUUCHI, E., KOSAKO, Y., YANO, I., HOTTA, H. \& NISHIUCHI, Y. Transfer of two Burkholderia and an Alcaligenes Species to Ralstonia gen nov. - Proposal of Ralstonia pickettii (Ralston, Palleroni and Doudoroff, 1973) comb. nov., Ralstonia solanacearum (Smith, 1896) comb. nov. and Ralstonia eutropha (Davis, 1969) comb. nov. Microbiology and Immunology 39:897904. 1995. 